\title{
PRÁTICAS ESPACIAIS E CONSUMO: DINÂMICAS DE REDEFINIÇÃO EM CIDADES MÉDIAS POLICÊNTRICAS
}

Heloísa Mariz Ferreira ${ }^{1}$

Resumo: Analisamos redefinições de práticas espaciais de consumo nas cidades médias de Marília, Presidente Prudente e São Carlos, que têm atraído investimentos relativos ao comércio e aos serviços. As redefinições estão submetidas a transformações na acumulação do capital, com novas escalas de atuação, e na sociedade, com novo papel adquirido pelo consumo, repercutindo e tendo como condição a complexificação da estrutura urbana e de processos socioespaciais. Contudo, a análise das práticas espaciais de consumo é indicativa da combinação de processos ligados às longas temporalidades e das escolhas cotidianas baseadas em elementos diversos, como o poder aquisitivo, a adoção de inovações em bens e serviços e espaços de consumo e os produtos a serem adquiridos.

Palavras-chave: Práticas espaciais. Consumo. Centro. Centralidade. Cidades Médias.

\section{SPATIAL PRACTICES AND CONSUMPTION: DYNAMICS OF REDEFINITION IN POLYCENTRIC INTERMEDIATED CITIES}

Abstract: We analyze the redefinition of spatial consumption practices in Marília, Presidente Prudente, and São Carlos, intermediated cities of São Paulo State that attracted investments from the economic groups related to commerce and services. The redefinitions are subjected to transformations in both capital accumulation (with new scales of action) and society (with new role acquired by consumption). This leads to complex urban structure and new sociospatial processes. Although the spatial consumption practices exists a combination between processes linked to long temporalities and everyday choices of complex generalization. This illustrates not only the purchasing power but also, for example, the importance of the products to be acquired.

Keywords: Spatial practices. Consumption. Centre. Centrality. Intermediated cities.

\section{PRÁCTICAS ESPACIALES Y CONSUMO: DINÁMICAS DE REDEFINICIÓN EN CIUDADES MEDIAS POLICÉNTRICAS}

Resumen: Analizamos redefiniciones de prácticas espaciales de consumo en las ciudades medias de Marília, Presidente Prudente y São Carlos, que han atraído inversiones relacionadas al comercio y a los servicios. Las redefiniciones están subsumidas a transformaciones en la acumulación del capital con nuevas escalas de actuación, y en la sociedad con nuevo papel adquirido por el consumo, repercutiendo y teniendo como condición la complejización de la estructura urbana y de procesos socioespaciales. Sin embargo, el análisis de las prácticas espaciales de consumo es indicativo de la combinación de procesos vinculados a las largas

1 Universidade Estadual Paulista "Júlio de Mesquita Filho", Campus de Presidente Prudente, Departamento de Geografia, Presidente Prudente, Brasil, heloisamariz@gmail.com, https://orcid.org/0000-0002-5360-1374 
temporalidades y de elecciones cotidianas basadas en elementos diversos, como el poder adquisitivo y los productos a ser adquiridos.

Palabras clave: Prácticas espaciales. Consumo. Centro. Centralidad. Ciudades Medias.

\section{Introdução}

A partir da análise de Marília, Presidente Prudente e São Carlos, tratamos, no presente artigo, da redefinição de práticas espaciais de consumo. Tal redefinição se encontra vinculada tanto aos processos da acumulação, com suas tendências à centralização do capital nos termos propostos por Lencioni (2008), quanto ao novo papel do consumo na sociedade contemporânea enquanto instrumento de diferenciação social, como aponta Baudrillard (1991).

As dinâmicas de centralização do capital consistem, segundo Lencioni (2008), no maior controle do capital e de sua valorização, com incremento da capacidade de gerenciamento de unidades territorialmente distantes, do que podemos exemplificar franquias e filiais, como lojas Magazine Luiza, Hering, Renner, Chiquinho Sorvetes e Subway. Isso possibilita, como concluíram Lozano e Sposito (2015), desconcentração espacial e incremento de papéis e funções a centros urbanos não metropolitanos, como as cidades médias.

Por outro lado, as dinâmicas de centralização do capital e desconcentração espacial fomentam e são condicionadas pela importância adquirida pelo consumo na sociedade contemporânea, com crescente expansão a camadas sociais (LIPOVETSKY, 2007), graças ao crédito e à manipulação de signos (BAUDRILLARD, 1991).

Nesse contexto, atinente sobretudo aos meados do século $X X$, surgem os primeiros shopping centers e hipermercados, sendo que no Brasil a multiplicação dessas duas tipologias de espaço de consumo se deu, quanto aos primeiros, nos anos de 1980, conforme Pintaudi (1989), e, no que se refere aos segundos, nos de 1990, de acordo com Silva (2005).

Em Marília, Presidente Prudente e São Carlos, shopping centers e hipermercados estão situados, em sua grande maioria, em eixos viários de expressiva fluidez ao transporte individual, como avenidas e rodovias, permitindo fácil acesso tanto aos consumidores das três cidades como os de municípios de suas regiões de influência. Com isso, ambos os espaços de consumo são representativos da criação de condições à redefinição de práticas espaciais e da centralidade do centro da cidade. 
De modo distinto dos subcentros, que tipicamente apresentaram relações de subordinação ao centro da cidade, as áreas centrais mais recentemente implantadas realizam relações de complementaridade e/ou concorrência, com expressiva atração de fluxos de pessoas, na conformação de estruturas policêntricas. Tais estruturas são por nós entendidas como aqueles marcadas pela coexistência de áreas centrais, de complexas relações, a partir, sobretudo, da implantação de grandes superfícies comerciais e de serviços.

Para além da quantificação dos fluxos, que possibilita mensuração da expressão de centralidade, a análise de práticas espaciais de consumo nos permite a compreensão da redefinição de modos de apropriação da cidade para fins de consumo, cada vez mais relacionados a processos de segmentação e fragmentação socioespaciais, como já apontado por Sposito e Góes (2013), com alterações na realidade urbana e cotidiana, nos termos propostos por Lefebvre (1991).

É por essa razão que nos valemos de dados quantitativos e qualitativos, por meio da análise de entrevistas realizadas com citadinos, que tiveram suas identidades resguardadas por meio da utilização de nomes fictícios, e questionários aplicados em escolas públicas e particulares das três cidades, produzidos no âmbito do Projeto Temático "Lógicas econômicas e práticas espaciais contemporâneas: cidades médias e consumo" de que fomos parte, para o entendimento de dinâmicas que envolvem informações não quantificáveis e explicativas de processo de redefinição.

Além desta breve introdução, o artigo é composto pelo tópico seguinte, no qual abordamos os processos de reestruturação espacial, significativos de mudanças na estruturação das três cidades estudadas, a partir da emergência de novas áreas centrais e alteração do conteúdo do centro. Este tópico é sucedido pela discussão acerca de práticas espaciais e do consumo na sociedade contemporânea, o que enseja considerações sobre práticas espaciais de consumo. Por fim, realizamos apontamentos a respeito da materialização das transformações aludidas sobre a produção da cidade e das práticas espaciais de consumo.

\section{Reestruturação espacial e cidades médias}

As mudanças econômicas, políticas e culturais que tiveram princípio nas últimas décadas do século XX promoveram reestruturações espaciais. No âmbito da rede urbana, é ilustrativa a ampliação da divisão territorial do trabalho, com 
incremento das dinâmicas de especialização e intensificação de complementaridades.

Ao tratar de cidades médias, Sposito (2007) assinalou transformações concernentes a novos papéis e funções destes centros na rede urbana, que implicam reestruturação urbana, relativa às "[...] formas como as cidades se posicionam nas redes, tendo em vista que diferentes agentes econômicos e sujeitos sociais atuam, movimentam-se e tomam decisões, aumentando as articulações [...]" (SPOSITO, 2011, p. 4).

O incremento de papéis e funções das cidades médias no processo de reestruturação urbana pode ser explicado por suas situações geográficas, como frisaram Sposito e Góes (2013). As cidades que compõem nosso recorte territorial estão localizadas em diferentes parcelas do estado de São Paulo. Marília e Presidente Prudente estão situadas em parcelas menos densas, no que diz respeito à presença de centros urbanos importantes, o que propicia expressiva influência regional, sobretudo por Presidente Prudente. Por outro lado, São Carlos está mais próxima às metrópoles de São Paulo e Campinas e a cidades médias de significativas funções, a exemplo de Araraquara e Ribeirão Preto.

De modo indissociável, o processo de reestruturação urbana está ligado ao de reestruturação das cidades, que passaram a apresentar novas lógicas de estruturação, conforme apontou Sposito (2007), são marcadas pela complexificação da relação entre centro e periferia, com a implantação de grandes superfícies comerciais e de serviços, foco desta seção do texto.

Em imanente articulação, portanto, entre as dimensões intra e interurbana, o surgimento das novas áreas centrais representou complexificação da estrutura, como identificamos em Marília, Presidente Prudente e São Carlos. Atendendo maior número de centros urbanos, Presidente Prudente exibiu precedência na implantação de novos espaços de consumo, já a partir da década de 1980, e em número mais elevado, com repercussões significativas no centro da cidade. Marília conta com igual número de shopping centers, porém inferior presença de hipermercados, em comparação à cidade de Presidente Prudente, apresentando centro de centralidade expressiva. Por fim, São Carlos exibe apenas um shopping center e ainda menor número de hipermercados, com centro da cidade de relevante atração de consumidores, embora coexistente à constituição de 'Novo centro'.

Selecionamos, com efeito, Marília, Presidente Prudente e São Carlos em função das três cidades exercerem, na rede urbana, papéis de intermediação e 
similares portes da população urbana² (207.373; 203.370; e 213.070 habitantes, respectivamente), em situações geográficas, entretanto, distintas. Isso nos permitiu apreender de elementos comuns na dinâmica de redefinição de práticas espaciais de consumo em cidades médias e particularidades atinentes à intensidade das transformações em suas estruturas espaciais.

Nestas cidades, as grandes superfícies comerciais e de serviços consistem em hipermercados e shopping centers. Sem considerarmos a clássica compreensão da denominada Escola de Chicago acerca de central área enquanto espaço formado pelo Central Business District e peripheral zone, entendemos hipermercados e shopping centers como áreas centrais já que manifestam expressiva centralidade, como demonstraremos ao discorrermos acerca das práticas espaciais de consumo.

Entre os dois equipamentos, chamamos atenção para os shopping centers, voltados a público específico, que, embora não dispensem segmentos de médios rendimentos, como pontua Góes (2016), e sejam incapazes de previsão e proibição de usos, com o consumo ou frequentação de citadinos de baixa renda, promovem dinâmicas de segmentação socioespacial dos espaços de consumo, em intensidades distintas entre as três cidades que analisamos.

Os shopping centers agregam outros diversos capitais externos, que apresentam dinâmicas de centralização do capital e desconcentração espacial de suas atuações, por meio de novos modos de organização, como franquias e filiais, em lógicas espaciais que primam por localização em novos espaços de consumo, notadamente no caso de franquias, uma vez que, segundo Porto-Sales (2014), a escolha do local de implantação é mensurada nos contratos de franqueamento e diz respeito ao público almejado e o potencial de lucratividade.

Se a formação do centro se faz por meio de processo, concomitante, em boa parte das vezes, à própria constituição da cidade, pela aglomeração sucessiva de estabelecimentos e do incremento de sua centralidade, os shopping centers correspondem, de acordo com Sposito (2013), à área central cuja implantação se dá no tempo curto, de modo planejado, em impactos rápidos e intensos sobre a estruturação urbana.

A implantação de shopping centers é orientada, de acordo com Silva (2017, p. 203), por interesses de agentes imobiliários e fundiários, que juntos buscam localizações favoráveis a amplas construções, criação de amenidades e incremento da acessibilidade, com capacidade de transformação das áreas adjacentes.

\footnotetext{
${ }^{2}$ Conforme o Censo demográfico de 2010 do Instituto Brasileiro de Geografia e Estatística (IBGE).
} 
Também situados, de modo predominante, em áreas periféricas, os hipermercados correspondem a ações de agentes de capitais externos e exercem, segundo Gomes (2016, p. 19), funções anteriormente realizadas por diversos varejistas. Em comparação aos supermercados, de acordo com Silva (2005), os hipermercados exibem maiores dimensões, atrelados à maior diversidade de bens ofertados, não mais restritos a artigos de alimentação, higiene e limpeza, pois atuam na comercialização de eletroeletrônicos e produtos do vestuário, por exemplo.

Tal distinção entre supermercados e hipermercados implica maior capacidade de atração de consumidores, de distintos segmentos socioeconômicos, e, por conseguinte, de redefinição das práticas espaciais de consumo quando de suas implantações, ao constituírem os principais espaços para compras de alimentos.

Representativas das mudanças atreladas ao surgimento de novas áreas centrais, como shopping centers e hipermercados, as cidades de Marília, Presidente Prudente e São Carlos exibem crescimento e porte demográfico semelhantes, mas dinâmicas distintas do centro e da centralidade intraurbana.

Marília consiste em cidade que, a despeito da implantação de dois shopping centers e alguns hipermercados, apresenta centro que permanece enquanto principal área central, com lógicas econômicas e práticas espaciais que a privilegiam, de modo predominante, apesar da relevância do processo de desconcentração de atividades comerciais e de serviços e, como verificou Dal Pozzo (2011), segmentação socioespacial.

As transformações na estrutura se mostram mais intensas em Presidente Prudente, onde observamos número superior de hipermercados, presença de dois shopping centers, sendo um deles o Prudenshopping, capaz de atendimento de ampla gama de segmentos socioeconômicos e, devido à localização de lojas voltadas a público de médio poder aquisitivo, que fomentam o consumo com parcelamentos e concessão de empréstimos, como Renner e $C \& A$, apresenta alteração mais brusca do conteúdo do centro.

Com efeito, em Presidente Prudente, o atributo do centro da cidade enquanto o principal espaço de consumo é relativizado, com papel menos importante que o verificado em Marília, quanto ao seu privilégio em escolhas de citadinos em suas práticas espaciais de consumo.

Se essas duas cidades apresentam implantações de grandes superfícies comerciais e de serviços, que propiciaram e foram condicionadas por redefinição de 
práticas espaciais de consumo, em São Carlos, além de dois hipermercados, apenas um shopping center foi construído, em processo de reestruturação espacial menos intenso. Entretanto, foi neste caso que anseios por separação socioespacial e práticas espaciais de consumo concorreram para a formação de áreas centrais por meio de iniciativas individuais de comerciantes e prestadores de serviços.

Destacamos área formada a partir da expansão do centro, que constituída pela Avenida São Carlos, em confluência com a Rua 15 de Novembro e a Avenida Carlos Botelho, apresenta aglomeração de atividades que exibe tendência à segmentação socioespacial, dinâmica favorecida pela proximidade à concentração de residências de médio a alto padrão, em bairro de fácil acesso a espaços residenciais fechados.

Embora não originada por ações de empreendedores imobiliários, tal qual seria em um shopping center, esta área central concentra, de modo semelhante, franquias e filiais, também ligada, portanto, ao consumo contemporâneo como produto da mundialização do capital, apoiado na financeirização da economia.

Ao configurarem maior adequação ao período em que o consumo adquire novas qualidades e o crédito, grande expansão, as novas áreas centrais promovem redefinição da centralidade intraurbana. Tais áreas centrais constituem o resultado da atuação de agentes imobiliários que se valem, como abordaremos a seguir, de publicidade para além dos valores de uso atinentes, o que se combina à produção não mais voltada a mercados consumidores de massa.

\section{Práticas espaciais de consumo}

Em meio às grandes transformações do capital, destacamos a pertinência da análise da redefinição de práticas espaciais de consumo, ligadas a importantes mudanças sociais, no intento de compreendermos repercussões no espaço das cidades e no tempo cotidiano dos grandes processos contemporâneos, não como simples palco de grandes transformações, mas como evidência de descompassos espaço-temporais do alcance destas.

Entre os pesquisadores que se valem da noção de práticas espaciais, Lefebvre (1991) o faz inserindo-as na discussão mais ampla da produção e reprodução do espaço, entendendo-as em articulação imanente aos processos espaciais. A explicação das práticas, como a dos processos exige, com isso, conexão recíproca. 
Apoiando-se nas contribuições deste autor, Souza (2010) entende que as práticas espaciais correspondem a "práticas sociais densas de espacialidade", mais diretamente ligadas ao espaço. A partir disto é que realizamos nosso esforço analítico de compreensão dos impactos de transformações sociais e econômicas, vinculadas, sobretudo, ao consumo, nas escolhas dos citadinos para os espaços de realização das práticas atinentes, em forte combinação entre processos e práticas, bem como entre práticas sociais e práticas espaciais.

As práticas espaciais dizem respeito, para Lefebvre (1991), ao cotidiano, por constituírem associação entre espaço percebido, realidade cotidiana e realidade urbana, sendo a realidade cotidiana ligada ao uso do tempo e a realidade urbana, aos percursos realizados pelos citadinos. Ao mesmo tempo, esta associação realiza e pressupõe a separação entre os lugares, o que compreende uma autonomização do espaço, enquanto realidade.

Nossas análises de práticas espaciais de consumo em Marília, Presidente Prudente e São Carlos indicaram amálgama complexa entre transformações e permanências quanto às realidades cotidiana e urbana, com a realização de práticas de consumo no centro e adoção de hábitos de compras em novos espaços por ampla parcela dos citadinos, inclusive dos inseridos em camadas de baixo poder aquisitivo, no que se refere, especialmente, à aquisição de produtos alimentícios em hipermercados.

Entretanto, não somente na busca por economia de tempo no cotidiano ou relativa aos bens e serviços a serem adquiridos, a redefinição de práticas espaciais tem se dado por recrudescimento de esforços de distinção social por meio do consumo. Neste sentido, Sposito (2013) defende que a implantação de novas áreas centrais, voltadas a públicos específicos, significou multiplicação dos contextos de interação social na realização do consumo, reforçando e ampliando, portanto, processos de separação socioespaciais.

Com efeito, ao buscarmos compreender as práticas espaciais de consumo, o fazemos no interesse pela seleção dos espaços de consumo, que se dá segundo diversos fatores, mas principalmente pelo poder aquisitivo, apreço a inovação de produtos e serviços e pelos artigos a serem adquiridos.

Para tanto, discorremos, a seguir, sobre as transformações observadas no papel do consumo na sociedade contemporânea, associado à publicidade e ao crédito, que repercutem em redefinições nas práticas espaciais concernentes. 


\section{Consumo e práticas espaciais}

Considerando os apontamentos tecidos na seção anterior, interessa-nos a análise das práticas espaciais em Marília, Presidente Prudente e São Carlos, pelas transformações que o consumo adquiriu na sociedade contemporânea, em uma trajetória que parte de seu papel banal para aquele que se mostra central na vida de diferentes indivíduos (BAUMAN, 2008), em complexa articulação das dimensões econômica, social, política e cultural (RETONDAR, 2007).

Com princípio em meados de 1880, as transformações do consumo se deram, de acordo com Lipovetsky (2007), graças a inovações tecnológicas substanciais que permitiram uma periodicidade e aumento contínuo da produção, em profusão de artigos. Por outro lado, na esfera da troca, era nos grandes armazéns, segundo Baudrillard (1991), que os inúmeros artigos eram expostos, para efeitos de sedução e como expressão de uma sociedade pautada na abundância e no desperdício, promovendo o consumo como instrumento de manipulação de signos e busca por diferenciação social.

Posteriormente a isso, nos anos de 1950 e 1960, ganhou importância, como destaca Lipovetsky (2007), uma ampliação da afluência a camadas sociais antes preteridas, na constituição de sociedade de consumo de massa, que foi sucedida, porém não substituída, a partir da década de 1970, pelo incremento das economias de escopo, conforme Harvey (1992), com a criação de nichos de mercado.

Essa curva ascendente do consumo, em direção ao alargamento e complexificação, somente pode se efetivar, e ainda se encontra em realização, por meio do constante estímulo ao consumo, pela publicidade e pelo crédito.

Ao incorporar outras qualidades que aquelas circunscritas ao uso do produto, a publicidade é instrumento de agentes da produção e distribuição, de acordo com Retondar (2007), ao se mostrar capaz de influenciar práticas de consumo. Para além de explícitas propagandas, em espaços reservados em revistas e programações da TV, a publicidade opera, segundo Padilha (2006), no cinema e outras esferas da comunicação, por meio da difusão de modas e estilos de vida. A partir disso é que grandes marcas estendem suas escalas de atuação, em novos modos de organização, como filiais e, mais recentemente, franquias, estas concentradas sobretudo em shopping centers.

Se o consumo é continuamente estimulado pela publicidade, é por meio do crédito que se oferece a condição à sua realização, ao reverter, conforme Bauman 
(2010), a ordem até então seguida entre pagamento e usufruto, para a satisfação imediata de necessidades, induzidas ou não. Em função disso, como apreendemos da análise das três cidades de nossa pesquisa, as práticas de consumo são marcadas por constantes preocupações quanto possibilidades de crédito e extensão de parcelamentos, em conformidade, como apontaremos adiante, às mudanças vinculadas à crescente financeirização da economia, como apontou Lazzarato (2013).

$\mathrm{Na}$ produção do espaço urbano, essas transformações estão ligadas à implantação de áreas centrais planejadas para o estímulo às compras e fruição de serviços, que constituem novas opções às práticas espaciais de consumo. Embora tais práticas tenham apresentado mudanças expressivas, dão-se combinadas a permanências, não se tratando de novas práticas, mas de redefinições, como apontaremos.

Esta constatação nos faz concordar com Certeau (1998), quando adverte que, para além da compreensão dos consumidores enquanto indivíduos passivos frente às grandes transformações na produção, realizam multiplicidade de escolhas, a partir da contínua combinação entre a aceitação dos impulsos ao consumo tecidos pelo capital, em estratégias como denomina o autor, e o que, na prática, os citadinos fazem com as imposições que recebem, por meio de táticas. Certeau (1998) argumenta, então, que os trajetos na cidade são diversificados e, por vezes, 'indeterminados'.

No sentido de empreender uma análise de práticas espaciais de consumo em Marília, Presidente Prudente e São Carlos, analisamos, no tópico seguinte, escolhas tecidas cotidianamente pelos citadinos quanto aos espaços de consumo, chamando a atenção quanto às distinções entre elas baseadas em diferentes elementos, às particularidades das três cidades e à combinação entre transformações e permanências.

\section{Práticas espaciais de consumo em Marília, Presidente Prudente e São Carlos}

Nossa compreensão das práticas espaciais de consumo em Marília, Presidente Prudente e São Carlos se deu pela análise de questionários e entrevistas realizadas por membros do Projeto Temático. Aplicados em instituições de ensino públicas e privadas das três cidades, os questionários foram direcionados à identificação dos espaços de consumo escolhidos para as compras de alimentos, 
vestuário e eletroeletrônicos e serviços de alimentação, saúde e educação, associados à frequência das práticas e os meios de transporte utilizados para sua realização. Em Marília, Presidente Prudente e São Carlos, 176, 186 e $176^{3}$ questionários foram respondidos, respectivamente.

Os dados dos questionários foram organizados por membros do Projeto Temático em tabelas, por meio das quais coletamos informações de indagações selecionadas, cujas respostas foram organizadas em porcentagens, para melhor comparação entre elas e entre as três cidades.

As entrevistas semiestruturadas foram realizadas com residentes de diferentes perfis, considerando faixa etária, estado civil, gênero, nível de renda e bairro de moradia. Posteriormente, as mesmas foram transcritas, o que nos possibilitou tecermos análise, discorrida ao longo do presente tópico. Ao todo foram realizadas, para atender os distintos perfis, 17, 14 e 15 entrevistas em Marília, Presidente Prudente e São Carlos, respectivamente.

A partir dos procedimentos aludidos, destacamos a combinação de transformações e permanências das práticas espaciais, com consumo em novas áreas centrais, mas também ida ao centro por parcela expressiva de citadinos, em movimentos contrários à perda de sua importância no conjunto da cidade e aos processos de segmentação e fragmentação socioespaciais.

Essa complexa amálgama entre transformações e permanências é passível de apreensão segundo diversos elementos, dentre os quais destacamos: a) o poder aquisitivo; b) a adesão à inovação de produtos e espaços de consumo; e c) os bens e serviços a serem adquiridos, associados ao ritmo de tais práticas.

Posterior a isso, analisamos as áreas centrais utilizadas pelos citadinos em suas práticas espaciais de consumo, como síntese da referida amálgama, para tecermos comparações entre Marília, Presidente Prudente e São Carlos.

Tratando, de início, das diferenças quanto ao elemento a, atrelado à capacidade de desembolso nas compras de distintos bens e aquisição de serviços, apontamos que as práticas espaciais de consumo dos citadinos dos segmentos de elevado poder aquisitivo exibem mudanças expressivas. Identificamos a realização de trajetos cotidianos mais recorrentes a shopping centers e hipermercados, embora

\footnotetext{
${ }^{3}$ Embora os questionários não sejam estatisticamente representativos, o número semelhante de formulários respondidos em Marília, Presidente Prudente e São Carlos, associado aos portes demográficos semelhantes das três cidades, permitiu-nos realizar comparação acerca das escolhas pelos espaços de consumo.
} 
a ida ao centro seja mencionada, especialmente pelos que residem na área ou bairros vizinhos e para a compra de eletroeletrônicos e eletrodomésticos.

São ilustrativas quanto a isso as práticas de Fabrícia e Lorena, mãe e filha, respectivamente, com rendimento mensal em torno de $R \$ 5.000,00$, residentes em São Carlos, na Vila Prado, bairro em que está situado um consolidado subcentro. Suas práticas são marcadas por mudanças nas últimas décadas, com diminuição da ida ao centro e incremento de consumo no subcentro próximo à residência e no Shopping Iguatemi.

Moradores dessa cidade, também inseridos neste segmento, relataram práticas na área central formada a partir da expansão do centro, o denominado 'Novo Centro', que apresenta tendência à segmentação socioespacial.

Entrevistados residentes nas três cidades que privilegiam novas áreas centrais fizeram referência a lojas de marcas nacional e internacionalmente conhecidas, como TNG, Vizzano, Calvin Klein e Hering e mencionaram realização do lazer, especialmente serviços de alimentação e de cinemas, o que vai ao encontro dos atributos de espaços como shopping centers em "[...] gerar desejos, através de imagens, garantindo apenas satisfação parcial via consumo, mas ampla satisfação via acesso visual (ver e ser visto), como um desejo dirigido, aparentemente sem tensão [...]" (GÓES, 2016, p. 67).

Ainda que nenhum dos entrevistados tenha explicitado busca por distinção social, são bastante sugestivos os padrões relativamente díspares de práticas espaciais de consumo, em comparação às indicadas por citadinos de poder aquisitivo inferior, como demonstraremos adiante. $O$ que nos faz compartilhar da ideia de Baudrillard (1991), quando assinala o consumo enquanto elemento de diferenciação social, por meio da adesão a códigos e signos, ainda que, mais recentemente, a busca por status se associe a outros elementos, como já aponta Lipovetsky (2007).

Por outro lado, e como mais um fator indicativo de segmentação dos espaços de consumo nas três cidades que analisamos, assinalamos que o público consumidor do centro é majoritariamente composto pelas camadas de médio a baixos rendimentos, que exibem práticas pautadas em precauções sobre preços, com referências constantes a lojas reconhecidamente populares, a exemplo da Torra Torra e Pernambucanas.

São exemplares os relatos de Jorge, 49 anos, com renda mensal de aproximadamente $R \$ 3.000,00$ e Nicole, 26 anos, com renda de $R \$ 1.500,00$, ambos 
moradores de Marília, que manifestaram consumo frequente no centro, em função dos preços praticados, mais baratos em comparação àqueles realizados em shopping centers.

É interessante notar como os dois citadinos fazem suas escolhas em referência a experiências passadas, suas ou de familiares, com dívidas de extravagâncias em compras, o que os faz manter constantes preocupações quanto aos gastos e, especialmente no caso de Nicole, posição crítica em relação ao consumo ostensivo.

Para alguns entrevistados, o poder aquisitivo também resulta em não pertencimento a shopping centers, mas anseios de práticas de consumo, caso apresentassem melhores rendimentos, o que tem sido contornado por parcela de consumidores por meio da compra em lojas que oferecem crediário e extensos parcelamentos, como é o caso das lojas C\&A, Renner e Riachuelo. Esse movimento contrário à segmentação socioespacial, que denota um caráter não absoluto do processo, foi observada sobretudo em Presidente Prudente.

A tendência maior de segmentação dos espaços de consumo, com padrões distintos de práticas espaciais conforme o poder aquisitivo, é relativizada por adesões díspares a inovações de produtos e serviços e dos espaços de consumo, o elemento b. Isto confirma o apontamento de Lipovetsky (2007, p. 19), ao identificar tendências contrárias ao consumo desenfreado, especialmente a partir dos anos 90 , quando passaram a ganhar relevância certo cuidado quanto a desperdícios, declínio do apego a marcas e preocupações aos preços, para além da irrestrita busca por status.

Nesse sentido, embora em menor número, alguns citadinos se posicionaram criticamente ao consumismo contemporâneo e relataram evitar compras em grandes lojas e exibem apreço a brechós, não somente como meio de contenção de gastos, mas posição contrária à ampla tendência de homogeneização de gostos e práticas de consumo.

Assim como a oposição de Nicole ao consumismo, que nos referimos anteriormente, este é o caso de Jéssica, residente em Marília, com renda mensal de aproximadamente $R \$ 18.000,00$, que consome no centro para compras urgentes, em feiras e supermercados, como o Pão de Açúcar, para aquisição de produtos naturais, e em brechós da cidade de São Paulo, para aquisição de vestuário diferenciado. 
As práticas espaciais de consumo de Jéssica evidenciam uma ressignificação do consumo, uma vez que embora dê preferência a compras de roupas usadas, as faz em estabelecimentos de São Paulo, que comercializam peças diferenciadas, o que não é encontrado em Marília. Nesta cidade, a entrevistada mencionou realizar consumo de artigos alimentícios em supermercado de alto padrão, reconhecido por sua oferta de produtos importados e orgânicos. Com efeito, em articulação a predileções que, embora não se encontrem em total desconexão a gostos massificados, permite a construção de individualidade, frente à multiplicidade de bens e serviços e espaços de consumo.

Em padrões ainda inseridos no elemento $b$, identificamos dessemelhanças de práticas espaciais conforme a faixa etária dos citadinos. Especialmente indivíduos mais velhos mencionaram consumo mais recorrente no centro, mesmo se inseridos em segmentos socioeconômicos de alta renda, em função da presença de estabelecimentos tradicionalmente frequentados. Por outro lado, como já apontamos, a adesão a novidades se mostra bastante frequente entre jovens, que exibem maior tendência ao consumo em novas áreas centrais. Isto é possível, como apontamos no tópico anterior, pela ampliação do crédito, a partir de bancos e financeiras, e oferta de extensos parcelamentos.

Um último fator de complexificação das práticas espaciais de consumo que destacamos consiste, enquanto elemento $c$, na distinção de tendências conforme os bens e serviços a serem adquiridos, associados ao ritmo de consumo. Selecionamos aqueles que são representativos de dinâmicas contrárias, que são às relativas a práticas de compras de alimentos, de artigos do vestuário e calçados e de eletroeletrônicos.

Para as compras de alimentos, a escolha por hiper e supermercados é generalizada, pois é feita por quase $100 \%$ dos citadinos das três cidades. Com menores porcentagens e situados em subcentros ou comércios de vizinhança, os mercados de bairro constituem opção para cerca de 40 a 60\%. Enquanto locais secundários, estão as compras a domicílio e as realizadas em feiras livres, ainda que com participações desiguais entre Marília, Presidente Prudente e São Carlos.

Por meio de análise de entrevistas com citadinos, identificamos que há predileções por um ou dois destes espaços, muitas vezes situados nas imediações do bairro residencial, consistindo a proximidade em fator considerado na escolha pelos espaços de consumo, que embora não corresponda a elemento impeditivo, 
mostra-se oportuno, positivo, a despeito da multiplicidade de opções e meios de transporte utilizados.

Tais práticas não compõem processos de segmentação socioespacial, já que em análise das entrevistas concedidas por citadinos não observamos diferenças expressivas no padrão de preferências por espaços de consumo e nenhum relato referente a interdições e percepção de não pertencimento.

Tendo em vista que hipermercados, supermercados e mercados de bairro estão localizados, majoritariamente, na periferia geométrica destas cidades, as práticas relativas a compras de alimentos são tecidas, de modo significativo, fora do centro, sendo parte, com isso, do processo de redefinição das práticas espaciais de consumo.

Combinando as compras mensais e as semanais, essas práticas são, de modo geral, muito frequentes, com expressivo predomínio das menções relativas às idas "Uma vez por semana", entre 50 e 30\%, "Duas vezes por mês", para cerca de $30 \%$ dos citadinos; e "Uma vez por mês", entre 10 e $25 \%$.

Já as práticas de consumo de produtos do vestuário e calçados são, de modo geral, menos frequentes, com predomínio expressivo de compras realizadas "De vez em quando", opção que alcança cerca de 60 a $70 \%$ no centro e em shopping centers e 80 a $90 \%$ em subcentros, camelódromos e compras a domicílio. Cabe mencionar que, para cerca de 10 a $20 \%$ dos citadinos, as compras são feitas "Uma vez por mês", "Duas vezes por mês" e "Uma vez por semana".

Distintamente, as práticas tecidas em supermercados exibem relevância de compras feitas "Uma vez por semana", no caso de Marília, e "Duas vezes por mês", em São Carlos, a despeito das expressivas porcentagens daquelas tidas "De vez em quando", em Presidente Prudente (83,3\%).

Já no que diz respeito às áreas centrais requeridas para as práticas espaciais ligadas às compras de artigos do vestuário e calçados, o centro é frequentado por cerca de 60 a 90\% dos citadinos, e os shopping centers, de 40 a $60 \%$, notadamente os de maiores dimensões e números de lojas. Com papéis secundários estão as compras a domicílio, em camelódromos, lojas de bairro e hiper e supermercados.

Realizadas, sobretudo, no centro, quando referentes a citadinos de menores rendimentos e de parcela das camadas de médio poder aquisitivo, e, por outro lado, por consumidores de maior poder de compras em shopping centers, as práticas espaciais relativas à aquisição de artigos do vestuário e calçados denotam tendência 
à segmentação socioespacial dos espaços de consumo, com distintas intensidades, todavia, nas três cidades que analisamos.

Em Presidente Prudente, observamos alteração mais significativa do conteúdo social do centro, o que se mostrou menos acentuado em Marília e em São Carlos. Nas três cidades, entretanto, verificamos, em relatos concedidos em entrevistas, propensão cada vez mais expressiva de consumo em espaços mais recentes e declínio da ida ao centro.

Quanto às práticas espaciais relativas às compras de eletroeletrônicos, destacamos a majoritária escolha pelo centro, em porcentagens superiores a $50 \%$ dos citadinos em Marília e Presidente Prudente, e aproximadamente 90\% para os consumidores de São Carlos, em movimento de reforço da centralidade do centro.

Para estas aquisições, os citadinos mostraram preferência por lojas de capital externo, como Ponto Frio e Casas Bahia, em função da concessão de crediário e cartões de crédito, bem como número mais elevado de prestações, como referido nas entrevistas, principalmente por consumidores de menores rendimentos.

De modo distinto às práticas relacionadas a compras de alimentos e artigos de vestuário e calçados, os citadinos dos segmentos de alta renda mencionaram que a aquisição de eletroeletrônicos se dá, em grande medida, no centro, também por meio de parcelamentos.

Apesar do predomínio de opções pelo centro, há menções a práticas de consumo em shopping centers, onde citadinos interessados por novos lançamentos e inovações de artigos de eletroeletrônicos podem mais facilmente encontrar estas características, especialmente em lojas especializadas, como My Store, da marca Apple.

Em geral, quanto ao consumo em camelódromos, citadinos informaram pouca preferência, explicada nas entrevistas pela qualidade duvidosa dos artigos, embora alguns poucos expressaram apreço a novidades relativas a suprimentos de informática.

Quanto ao ritmo das práticas referentes ao consumo destes artigos, verificamos periodicidade significativamente menor, mesmo quando tecidas no centro, a principal área utilizada, como já mencionamos. Para 80 a 90\%, as compras são realizadas "De vez em quando", enquanto que para menos de $10 \%$ as práticas se dão "Uma vez por mês", "Uma vez por semana" e "Duas vezes por mês".

Em suma, por meio da análise de práticas espaciais de consumo de alimentos, roupas e calçados e eletroeletrônicos, identificamos padrões díspares, em 
dinâmicas de redefinição, combinadas a permanências da frequência no centro, sendo o primeiro caso manifestação de transformações na centralidade urbana, com práticas realizadas, sobretudo, em super e hipermercados, localizados, principalmente, em periferias geométricas, próximos a boas vias de circulação de automóveis individuais.

A importância desta tipologia de áreas centrais é ainda mais significativa considerando que as práticas de consumo de alimentos são bastante frequentes, o que implica trajetos cotidianos pela cidade tecidos fora do centro, mais utilizado pelos citadinos em compras menos recorrentes, como as ligadas ao consumo de vestuário, calçados e eletroeletrônicos.

Com base em Lefebvre (1991), podemos afirmar que as práticas espaciais de consumo contemporâneas são características de realidade cotidiana marcada por realidade urbana pautada em trajetos múltiplos, que exibem transformações e permanências conforme diferentes elementos, em movimentos contrários e de reforço ao processo de segmentação socioespacial e perda de importância do centro da cidade.

Com efeito, a análise das práticas espaciais de consumo indica papéis distintos das áreas centrais em meio à complexificação das preferências dos citadinos, o que implica redefinição não somente das práticas, mas em função delas, também da centralidade intraurbana. Entre as três cidades que nos debruçamos, tais mudanças se dão em magnitudes dessemelhantes, como as três figuras seguintes demonstram. 
Marília SP. Mapa de Consumo. 2013

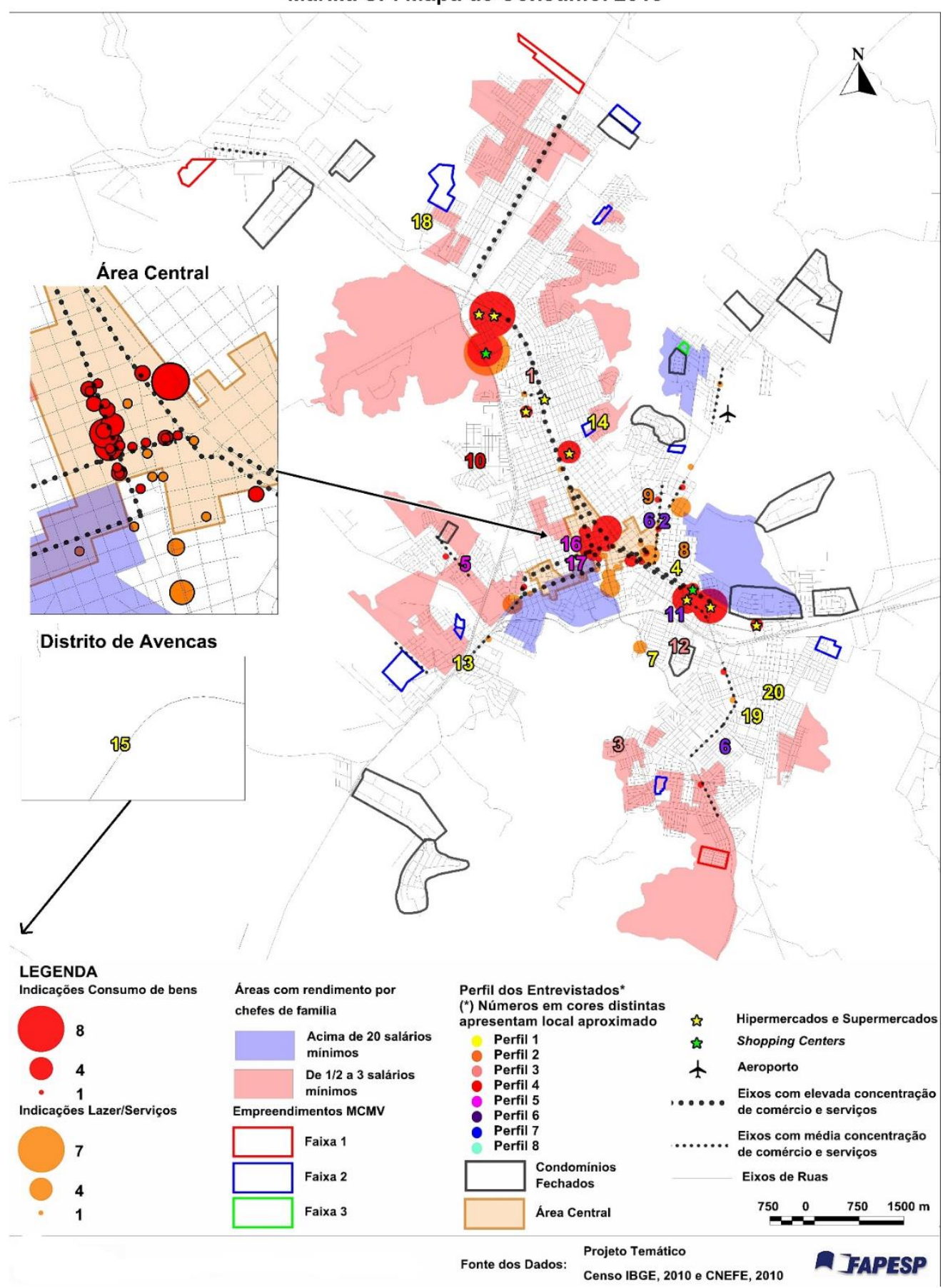

Figura 1. Marília (SP). Mapa de consumo, 2013.

Fonte: Projeto Temático "Lógicas econômicas e práticas espaciais contemporâneas: cidades médias e consumo". 
Presidente Prudente SP. Mapa de Consumo. 2013

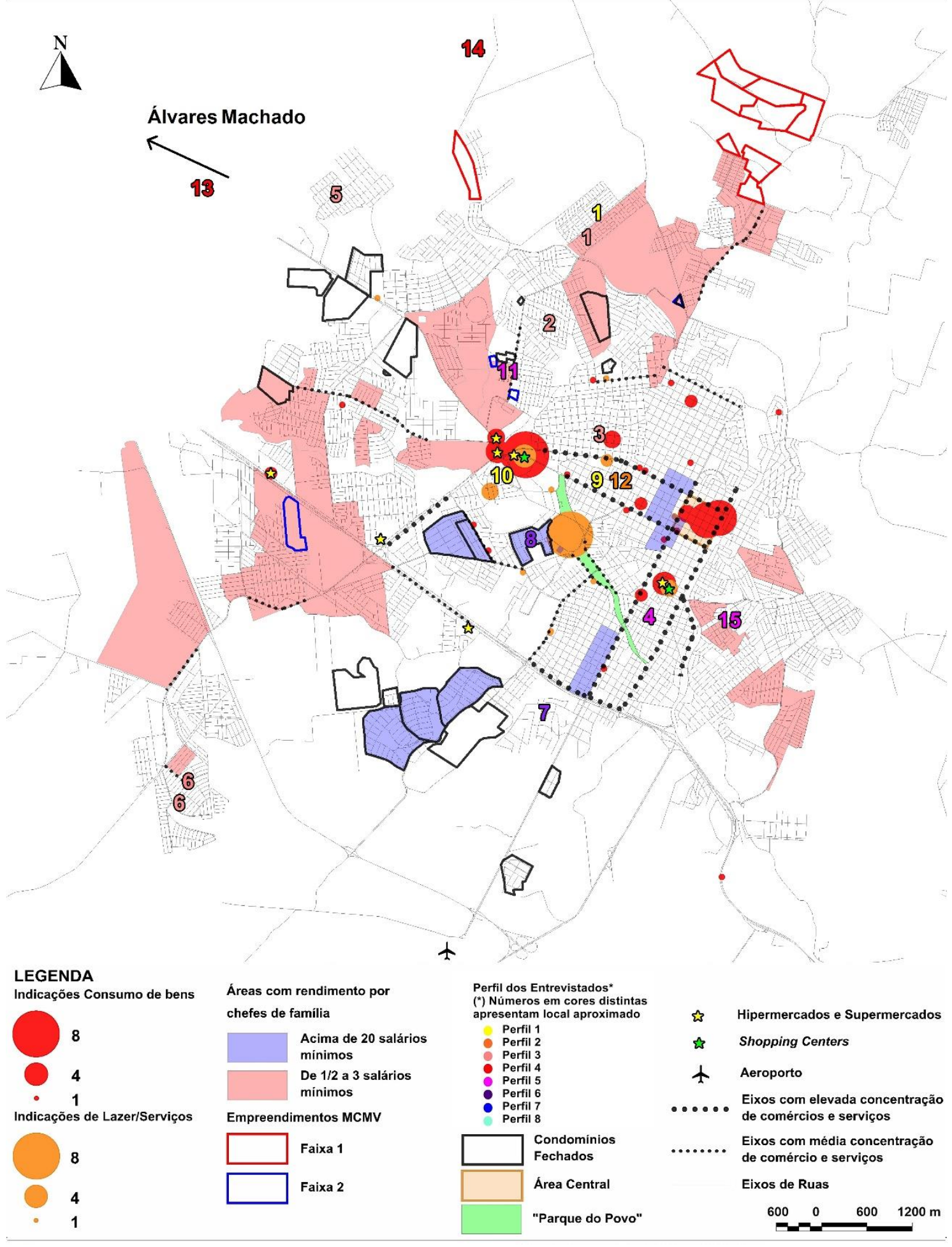

Figura 2. Presidente Prudente (SP). Mapa de consumo, 2013.

Fonte: Projeto Temático "Lógicas econômicas e práticas espaciais contemporâneas: cidades médias e consumo". 
São Carlos SP. Mapa de Consumo. 2013

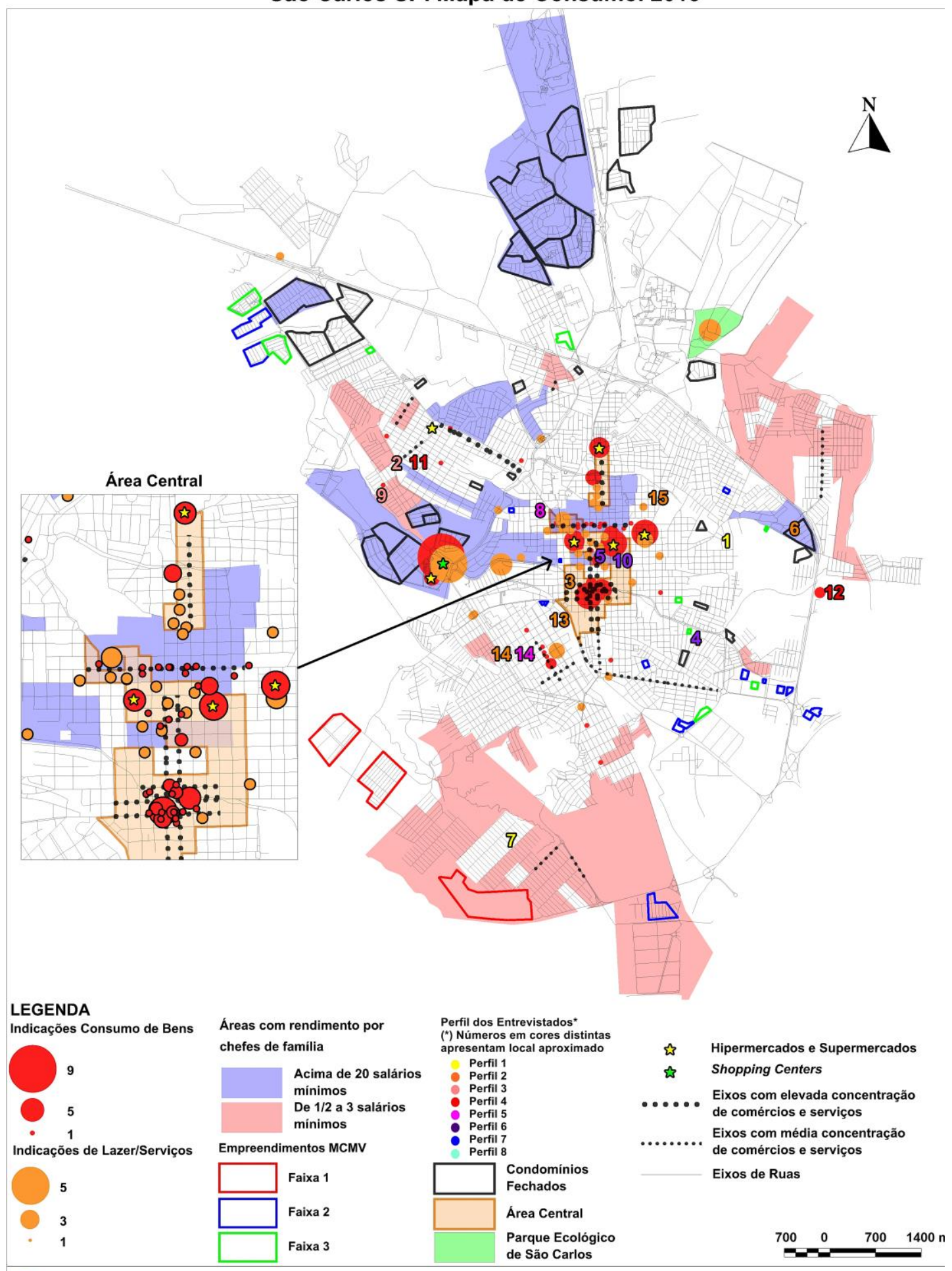

Figura 3. São Carlos (SP). Mapa de consumo, 2013.

Fonte: Projeto Temático "Lógicas econômicas e práticas espaciais contemporâneas: cidades médias e consumo".

No primeiro deles, referente à cidade de Marília, podemos verificar expressiva relevância do centro e dos dois shopping centers. Quanto ao centro, as práticas de consumo que nele se realizam privilegiam, especialmente, setor em que está situado o Calçadão da Rua Luís e, em menor medida, a Avenida Sampaio 
Vidal, como podemos verificar na imagem que amplia a representação das menções tecidas nas entrevistas. Em ambos os eixos, estão concentradas lojas franqueadas ou filiais de diferentes grupos econômicos, revelando os atributos desta tipologia de estabelecimentos na atração de consumidores, assim como denota o reforço da centralidade do centro, a despeito do consumo em diversas outras áreas da cidade.

Além do centro, tem importância bastante expressiva o Marília Shopping, localizado na porção Norte da cidade, onde está também situado o Hipermercado Atacadão, referido, sobretudo, para o consumo de alimentos. Também frisamos as menções a áreas situadas ao Sul do centro, em que estão localizados 0 Supermercados Tauste e o Hipermercado Confiança, igualmente requeridos para as compras destes bens, e localizados entre as avenidas Tiradentes e Esmeraldas, eixo de grande presença de franquias e filiais e onde está situado o Esmeralda Shopping, referido, de modo recorrente, pelos citadinos, cuja importância pode estar atrelada à proximidade a espaços residenciais fechados, como representado na figura.

Em Presidente Prudente, o centro e um dos dois shopping centers, o Prudenshopping consistiram nos espaços de consumo mais mencionados, como é possível notar na figura 2. Na primeira área central, as práticas são voltadas às compras de artigos do vestuário, calçados e eletrodomésticos, realizadas, não raramente, em franquias e, sobretudo, filiais de empresas com escala, em geral, nacional e regional, em semelhança ao observado em Marília.

Além dessas áreas centrais, sublinhamos as referências ao consumo nos hipermercados WalMart e Muffato Max, situados em proximidade ao Prudenshopping, espaço em que está localizado o hipermercado Carrefour, consistindo em setor da cidade de expressiva centralidade intraurbana.

Ainda na figura 2, identificamos expressividade das menções aos eixos 14 de Setembro e 11 de Maio, agregados pelo Parque do Povo, em certa contiguidade territorial, com grande concentração de comércio, mas principalmente de serviços, por meio de bares e restaurantes, que atendem parte significativa de citadinos em suas práticas de consumo, em importante manifestação de centralidade noturna.

$\mathrm{Na}$ terceira representação cartográfica, relativa a São Carlos, conferimos importância do centro, do 'novo centro' que se forma a partir da expansão daquela área, ao Norte, e do shopping center Iguatemi São Carlos. No que diz respeito ao centro, notamos expressividade de mais de um eixo, que embora inclua o Calçadão da Rua General Osório, também é observada em vias paralelas, como a Rua 
Episcopal, e, sobretudo, na Avenida São Carlos, que contribui para a extensão territorial do centro, ao Norte.

Nos três eixos, identificamos presença bastante expressiva de grandes lojas de eletrodomésticos, como Casas Bahia, Magazine Luiza e Cybelar, de artigos de vestuário e calçados, a exemplo das lojas Marisa, Seller e É $D_{+}$, de alimentos, de que são ilustrativos o Supermercado Dia e Sempre Vale Supermercados.

Ao Norte, a nova área central que se forma é também espaço mencionado pelos entrevistados. Em concentração mais rarefeita de atividades comerciais e de serviços e referências menos numerosas e recorrentes, se comparado ao centro, identificamos papel menos relevante nas práticas espaciais de consumo dos citadinos, em suas realidades urbanas, nos termos propostos por Lefebvre (1991).

Quanto ao Shopping Iguatemi, destacamos que sua importância é inferior se comparado ao Prudenshopping e Marília Shopping, embora igualmente seja citado em muitas das entrevistas para o consumo de alimentos, no Extra Hipermercados, assim como de serviços, especialmente o lazer, em praças de alimentação e no cinema. Neste sentido, embora corresponda a área central de atração expressiva de consumidores, a amplitude dos bens e serviços consumidos é menor.

No que se refere ao conjunto das três cidades, a série de figuras demonstra importância de outros setores, em referência ao consumo de serviços. Em Marília, número relevante de citadinos manifestou realização de práticas em estabelecimentos situados na Zona Leste, onde estão concentrados espaços residenciais fechados e dois eixos de comércio e serviços, as avenidas Brigadeiro Eduardo Gomes e Vicente Ferreira, e no Oeste, parcela com formação de comércios de vizinhança e expressiva aglomeração de instituições de ensino superior.

Em Presidente Prudente, podemos observar que a maior parte das práticas espaciais de consumo ligadas aos serviços, especialmente o lazer, é tecida nas avenidas 11 de Maio e 14 de Setembro, eixos com expressiva presença de bares e restaurantes noturnos. Já em São Carlos, para além do Iguatemi São Carlos, tais práticas se realizam em diversas áreas centrais e também em estabelecimentos dispersos.

Em síntese, apontamos papéis mais expressivos, quanto às práticas espaciais de consumo, do centro, shopping centers e hipermercados. Com efeito, são estas duas últimas áreas centrais que redefinem os papéis do centro da cidade e a centralidade intraurbana, se comparado, por exemplo, aos eixos de desdobramento da área central e subcentros. Entre as três cidades que analisamos, 
é em Presidente Prudente que as transformações se mostram mais intensas, ao passo que em Marília e São Carlos, o centro permanece, de modo mais intenso, como preferencial espaço de consumo.

\section{CONSIDERAÇÕES FINAIS}

Em análise que buscou articular processos e práticas, bem como práticas sociais e práticas espaciais, apoiando-nos em Lefebvre (1991) e Souza (2010), identificamos redefinição de práticas espaciais de consumo, atreladas a mudanças na acumulação do capital e novo papel do consumo na sociedade contemporânea.

Diante disso, nossa análise foi indicativa de novos trajetos tecidos para a realização do consumo, em escolhas por novas áreas centrais, notadamente shopping centers e hipermercados. No que se refere aos primeiros, a opção é utilizada especialmente por citadinos de alto poder aquisitivo, os mais jovens e para as compras de artigos do vestuário e calçados, ao passo que os segundos são requeridos, de modo generalizado, para a aquisição de alimentos.

Se isso implica alteração significativa da centralidade intraurbana, conformando policentralidade, apreendemos permanências quanto escolhas pelo centro da cidade, sobretudo por consumidores de baixos e médios rendimentos, mais velhos e para as compras de roupas, calçados, eletrodomésticos e eletroeletrônicos. Isso é indicativo da combinação entre transformações e permanências quanto às escolhas dos espaços para a realização das práticas de consumo.

Entre as três cidades, identificamos intensidades distintas das mudanças, com maior redefinição em Presidente Prudente, em comparação a Marília e São Carlos, em que conferimos maior importância do centro enquanto espaço de consumo, a despeito da magnitude dos processos contemporâneos.

\section{REFERÊNCIAS}

BAUDRILLARD, J. A sociedade de consumo. Lisboa: Edições 70, 1991.

O crédito. In:

O sistema de objetos. São Paulo: Perspectiva, 2006, p. 165-172.

BAUMAN, Z. Vida a crédito: conversas com Citiali Rovirosa-Madraso. Rio de Janeiro: Zahar, 2010.

Zahar, 2008.

Vida para consumo: a transformação das pessoas em mercadoria. Rio de Janeiro: Jorge 
CARRERAS, C. Consumir ou comprar. Repensando o consumo urbano à luz da globalização. Revista GEOUSP, n. 6, p. 81-94, 1999.

CERTEAU, M. de. A invenção do cotidiano. Artes de fazer. 3. ed. Petrópolis: Editora Vozes, 1998. DAL POZZO, C. F. Territórios da autossegregação e da segregação imposta: fragmentação socioespacial em Marília e São Carlos. 2011. 316 f. Dissertação (Mestrado em Geografia) - Faculdade de Ciências e Tecnologia, Universidade Estadual Paulista, Presidente Prudente, 2011.

GÓES, E. Shopping center: Consumo, simulação e controle social. Finisterra, LI, 102, 2016, p. 65 80.

GOMES, V. B. As atividades das grandes empresas do ramo supermercadista e a rede urbana brasileira no período recente. 2017. 507 f. Dissertação (Mestrado em Geografia) - Faculdade de Ciências e Tecnologia, Universidade Estadual Paulista, Presidente Prudente, 2016.

HARVEY, D. Condição pós-moderna. Uma pesquisa sobre as origens da mudança cultural. São Paulo: Edições Loyola, 1992.

LAZZARATO, M. La fábrica del hombre endeudado. Ensayo sobre la condición neoliberal. Buenos Aires: Amorrortu, 2013.

LEFEBVRE, H. The production of space. Malden: MA, 1991.

LENCIONI, S. Concentração e centralização das atividades urbanas: uma perspectiva multiescalar. Reflexões a partir do caso de São Paulo. Revista de Geografia Norte Grande, 39, 2008. p. 7-20. LIPOVETSKY, G. A felicidade paradoxal. Ensaio sobre a sociedade do hiperconsumo. Lisboa: Edições 70, 2007.

LOZANO, L. P. G; SPOSITO, E. S. Cidades médias e distribuição espacial do comércio de eletrodomésticos no Brasil. In: BELLET, C., SPOSITO, M.E.B., MELAZZO, E.S., LLOP, J.M.

(Org.). Urbanización, producción y consumo en ciudades medias/intermedias. 1ed.Lleida: Edicions de la Universitat de Lleida, 2015, v. 1, p. 79-106.

PADILHA, V. Shopping center: a catedral das mercadorias. São Paulo: Boitempo, 2006.

PINTAUDI, S. M. Templo da mercadoria. Estudo sobre os shopping centers do estado de São Paulo. 1989. 156 f. Tese (Doutorado em Geografia) - Universidade de São Paulo, 1989.

PORTO-SALES, A. L. A situação espacial de franquias na América do Sul: morfologia e centralidade urbana em cidades médias na Argentina, Brasil e Chile. 2014. 281 f. Tese (Doutorado em Geografia) - Faculdade de Ciências e Tecnologia, Universidade Estadual Paulista, Presidente Prudente.

RETONDAR, A. M. Sociedade de consumo, modernidade e globalização. São Paulo: Annablume, 2007.

SALGUEIRO, T. B. Cidade pós-moderna: espaço fragmentado. TERRITÓRIO. Rio de Janeiro: LAGET/UFRJ, n. 4, p. 39- 54, 1998.

. O consumo como motor de reestruturação urbana. Instituto de Estudos Geográficos (ed.) -

Dinamismos sócio-económicos e (re)organização territorial: processos de urbanização e de reestruturação produtiva, Coimbra, IEG, 1996, p. 435-452.

SANFELICI, D. M. As escalas de acumulação na produção das cidades. In: CARLOS, A. F. A.; VOLOCHKO, D.; ALVAREZ, I. P. (Org.). A cidade como negócio. São Paulo: Contexto, 2015, p. 121-144.

SANTOS, M. Metamorfoses do espaço habitado. Fundamentos teóricos e metodológicos da Geografia. São Paulo: Hucitec, 1994.

SILVA, C. H. C. O papel dos supermercados e hipermercados nas relações entre cidade, comércio e consumo. Geografia (Rio Claro), Rio Claro, v. 30, n.3, p. 610-625, 2005.

SILVA, W. R. Centralidade, shopping centers e reestruturação das cidades medias. In: MAIA, D.S.; SILVA, W.R.; WHITACKER, A.M. (Org.). Centro e Centralidade em cidades médias. São Paulo: Cultura Acadêmica, 2017.

SOUZA, M. L."Com o Estado, apesar do Estado, contra o Estado: Os movimentos urbanos e suas práticas espaciais, entre a luta institucional e a ação direta". Cidades, v. 7, p. 13-47, 2010.

SPOSITO, M. E. B. As cidades médias e os contextos econômicos contemporâneos. In: (Org). Urbanização e cidades: perspectivas geográficas. Presidente Prudente: [s.n.], 2001. p. 606643. 
Cidades médias: reestruturação da cidade e reestruturação urbana. In: SPOSITO, M. E. B. (org.). Cidades médias: espaços em transição. São Paulo: Expressão Popular, 2007. p. 233-253.

. Lógicas econômicas e práticas espaciais contemporâneas: Cidades médias e consumo. [Proposta de Projeto], 2011.

SPOSITO, M. E. B.; GÓES, E. M. Espaços residenciais fechados e cidades: insegurança urbana e fragmentação socioespacial. São Paulo: Editora Unesp, 2013.

. Segregação socioespacial e centralidade urbana. In: VASCONCELOS, P. A.; CORRÊA, R. L.; PINTAUDI, S. M.; A cidade contemporânea. Segregação espacial. São Paulo: Contexto, 2013. p. 61-94.

\section{NOTAS DE AUTOR}

\section{CONTRIBUIÇÃO DE AUTORIA}

Heloísa Mariz Ferreira - Concepção. Análise de dados, Elaboração do manuscrito, revisão e aprovação da versão final do trabalho

\section{FINANCIAMENTO}

A autora agradece à Fundação de Amparo à Pesquisa do Estado de São Paulo (FAPESP) pelo apoio financeiro no processo 2016/03757-3.

\section{CONSENTIMENTO DE USO DE IMAGEM}

Não se aplica.

\section{APROVAÇÃO DE COMITÊ DE ÉTICA EM PESQUISA}

Não se aplica.

CONFLITO DE INTERESSES

Não se aplica.

\section{LICENÇA DE USO}

Este artigo está licenciado sob a Licença Creative Commons CC-BY. Com essa licença você pode compartilhar, adaptar, criar para qualquer fim, desde que atribua a autoria da obra.

\section{HISTÓRICO}

Recebido em: 24-01-2019

Aprovado em: 10-09-2019 